Pathogenesis Review

\title{
Herpes latency, meningitis, radiculomyelopathy and disseminated infection
}

\author{
Joseph J Sasadeusz, Stephen L Sacks
}

\section{Introduction}

Genital herpes simplex virus (HSV) infection affects a large proportion of the population. A recent seroepidemiologic survey of individuals in the United States of America found that $16.4 \%$ of the population were seropositive for herpes simplex virus (HSV) type 2 (HSV-2). ${ }^{1}$ Most HSV-2 transmission originates with an asymptomatic partner. ${ }^{2}$ Because the majority of affected individuals are asymptomatic and experience periodic virus reactivations, a large reservoir of infectious virus persists.

A fundamental characteristic of all of the herpes viruses is their ability to achieve a state of latency from which they can reactivate. Viral reactivations become clinically evident in a minority of patients. Severity of disease manifestations are dependent upon a variety of virus and host factors. The site of inoculation will usually determine initial disease location(s), if the disease is symptomatic at the time of its primary acquisition. Sites of recurrent disease, on the other hand, are determined by the routing of neural pathways emanating from the site(s) of neuronal latency. For example, HSV type 1 (HSV 1) or HSV-2 may be inoculated initially at any site with subsequent local recurrences also possible in or near that location. Because the majority of human host interactions involve either genital or facial skin or mucous membranes, the majority of HSV disease is manifest on the face and/or genital region. The vast majority of genital herpes is caused by reactivation from latency of HSV-2. Primary genital disease, however, while more commonly caused by transmission of HSV-2, may often be caused by HSV-1, transmission occurring via genital-genital or oral-genital routes, respectively. The converse is true for orallabial disease which is predominantly HSV-1 and results from face-to-face contact.

Recurrent disease locations are determined by the nature of the individual's neural recurrence pathway, which, in turn, must also reflect the specific transmission event which identified the initial site of viral inoculation into the new host. Thus, disease manifestations may be highly variable. For example, oral-labial herpes in one person may be transmitted to any target in the new host which directly contacts the mouth. The most common site is the mouth or lips of the viral recipient. However, inoculation to the ophthalmic division of the trigeminal nerve may instead lead to ophthalmic HSV and recurrent keratitis or deeper stromal disease. Inoculation to the finger or hand may be a more likely end- point for an intensivist or a dental hygienist delivering mouth care. Infection of the cribriform plate and the overlying olfactory bulb, may lead to a less common, potentially lethal form of localized HSV infection, herpes encephalitis. Encephalitis passed via this route in adults is caused by HSV-1. HSV-2 encephalitis generally occurs in neonates and results from intrapartum transmission, and less commonly occurs in immunocompromised adults with disseminated infection. Just as the nature of the disease caused by mucocutaneous HSV depends upon the site of infection, HSV may cause a variety of neurological syndromes, ranging from aseptic meningitis to radiculomyelopathy, all of which are defined by the site(s) of involvement. This review will focus on these latter syndromes, specifically addressing what is known of their pathogenesis, manifestations and treatment.

\section{The biology of herpes simplex viruses}

HSV is a double stranded DNA virus approximately $150 \mathrm{~nm}$ in diameter. It is surrounded by a lipid envelope from which virus-specific glycoproteins protrude, surrounding an icosahedral protein capsid which houses the genome and an amorphous material known as the tegument which, in turn, contains a number of viral-encoded proteins. A number of clinical, epidemiological and biological differences allow distinction between $2 \mathrm{HSV}$ types, HSV-1 and HSV-2. ${ }^{3}$ Genital herpes can be caused by either HSV-1 or HSV-2. HSV-1 may account for between $7 \%$ to $50 \%$ of first episode lesions, depending on geographical location, but only causes $2 \%$ of recurrent genital herpes. ${ }^{4}$ Its genome is linear, approximately $150 \mathrm{~kb}$ long. There is a large degree of homology between the genomes of HSV-1 and HSV-2 with about $50 \%$ of the sequences being highly conserved. ${ }^{5}$

Infection is caused by inoculation of virus onto mucosal surfaces or skin with an epithelial breach. A new replication cycle of HSV commences with attachment of the envelope to cell surface heparan sulphate, fusion with the cell plasma membrane and liberation of nucleocapsids into the cytoplasm. These steps are mediated by membrane virus-derived glycoproteins. The virus then migrates to the nucleus where it is uncoated at nuclear pores and the naked DNA enters the nucleus and circularises. A prepackaged transactivator of transcription, VP16, then initiates the transcription of the first of a cascade of three sets of genes, the immediate early (IE) genes. These gene products then activate the next set of
Address correspondence to: Dr J J Sasadeusz

Accepted for publication 2 June 1994 


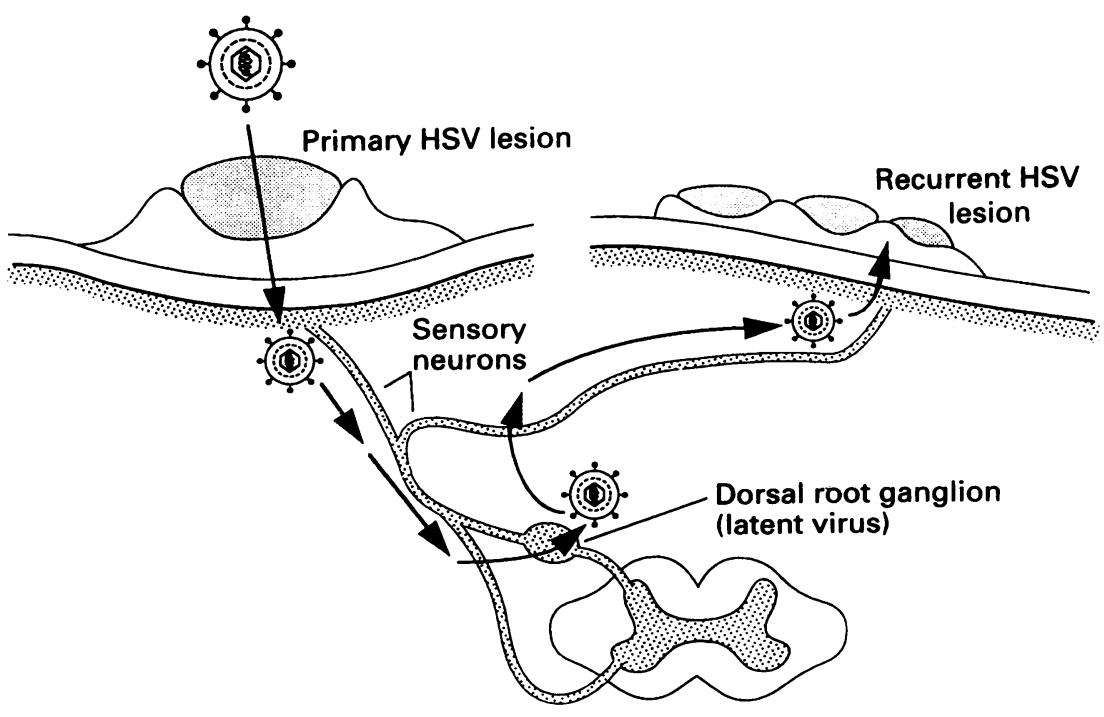

Figure 1 Schematic of pathways of development of HSV latency following primary infection and subsequent reactivation to initiate recurrences.

genes, the early genes, which are mainly involved in DNA replication and simultaneously downregulate cellular gene transcription. This initiates DNA replication which is carried out by a rolling circle mechanism to produce linear concatemeric DNA. ${ }^{6}$ The early genes initiate the transcription of the late genes which are predominantly structural. The DNA is then cleaved to an appropriate size and packaged. Finally, the virion acquires an envelope as it buds from the inner nuclear membrane and, after glycoprotein modification in the endoplasmic reticulum and golgi apparatus, leaves the cell. The generation of large numbers of virions in permissive cells is associated with cell death and completes the lytic cycle of the virus. ${ }^{7}$ Primary infection may be symptomatic or asymptomatic. In either case there may be sufficient viral replication to result in infection of terminal branches of sensory endings. It is unclear whether latency always results from peripheral mucocutaneous infection. The nucleocapsid is then transported centripetally inside axons to the cell body in sensory ganglia. ${ }^{89}$ At this stage, a limited degree of local replication occurs in ganglia and may extend to neighbouring neuronal and nonneuronal cells, some of which may demonstrate cytopathic effect. ${ }^{10-12}$ This replication is not necessary for the establishment of latency as replication-deficient mutants can establish latency with the same efficiency as wild type virus. ${ }^{13}$ The host immune system eventually controls the mucocutaneous viral replication and epithelial damage, resulting in resolution of the primary infection. Simultaneously, the pattern of gene expression changes, such that all genes responsible for viral replication are shut off, leaving only one region of the genome transcriptionally active to produce a family of transcripts known as latency-associated transcripts (LATs). ${ }^{14-16}$ At this time, infectious virus is undetectable except by ganglionic explantation; surface viral proteins are undetectable; and virus is latent, thereby evading both immune attack and currently available antiviral chemotherapies. As a measure of extent of latent infection, in situ hybridisation studies show that $0 \cdot 1-3.0 \%$ of human neurons contain LATs. ${ }^{1516}$ HSV may be subsequently reactivated from its latent state via certain $\mathbb{\Phi}$ trigger factors, some defined; others not. The virus then travels centrifugally to reinitiate productive infection at a mucocutaneous site. The recurrence is modified by a preexisting $\frac{}{\mathbb{2}}$ immune response, however. In cases where? primary disease was clinically evident, recur- $\overrightarrow{\bar{B}}$ rences are generally shorter and/or less intensethan the primary infection which led originally등 to the latent state. ${ }^{5}$ However, where the pri- $\frac{\bar{s}}{\overline{2}}$ mary infection was, itself, asymptomatic, $\stackrel{\oplus}{\varrho}$ reactivations may seem to be of equal or $\frac{\infty}{0}$ greater clinical intensity.

The nature of latency

A hallmark of all herpes viruses is their ability to establish latency. This group of viruses may= be subclassified according to the cell type. which supports their latent state. Because $\dot{\omega}$ HSV-1, HSV-2 and varicella zoster virus 8 (VZV) are neurotropic, they are classed as을 "alpha" herpes viruses.

Several important clinical observations have been made about the latent state. Both human and animal data demonstrate HSV-2 to reactivate much more frequently from $\stackrel{\Phi}{ }$ sacral latency compared with HSV-1. $\vec{\bullet}$ Conversely, HSV-2 reactivates less frequently from a trigeminal latent site. ${ }^{41718}$ These observations suggest that viral latency may result from a specific adaptation of a virus type. It is unclear whether these type-specific differ-\%ั ences are due to lower frequency rates of the $\stackrel{\varnothing}{\circ}$ establishment of latency or alternatively, type- $\overrightarrow{\overrightarrow{0}}$ dependent differences in rates of reactivation. 3 Reactivation rates do not vary between sexes, however, nor are they dependent upon the relative symptomatic severity of the primary episode. ${ }^{4}$ Studies of changing reactivation rates with time are contradictory. One study suggested a $50 \%$ reduction in recurrence rate $\bigcirc$ in men with a history of $>4$ years as opposed to those of 6-12 months duration ${ }^{4}$ while another suggested no difference in rates for individuals infected $>5$ years as opposed to those infected $<5$ years. ${ }^{19}$ Immune compe- 0 tence, however, seems crucial to the mainte- $N$ nance of latency. Patients with defects in cell-mediated immunity, including transplanto recipients and patients with the acquiredo immune deficiency syndrome (AIDS), suffer more frequent and more severe recurrences of HSV. ${ }^{20-23}$ Animal models show that immunesuppression predisposes to in vivo reactiva- $\overrightarrow{\mathbb{\mathbb { Q }}}$ tion. ${ }^{24}$ Furthermore, HSV reactivation may be predictably triggered by nonimmunosuppressive stimuli such as trauma to sensory nerves and ultraviolet light, ${ }^{26}{ }^{27}$ suggesting that neuronal disturbances are important in the mechanisms of reactivation. Despite recurring neuron-based reactivations, patients with frequent attacks of herpes labialis do not generally suffer neurological deficits in affected dermatomes. This would suggest that reactivations are not associated with destruction of 
the latently-infected, subsequently-reactivated neuron. ${ }^{28}$

The role of viral thymidine kinase in latency has been debated. While latent viral infection may be caused by viruses genetically unable to express viral thymidine kinase (TK), reactivation from latency requires TK in a mouse model of HSV $-1 .{ }^{29}$ Reactivations of TK-deficient HSV-2 without coexistent drug treatment pressure have been observed in some AIDS patients, however, suggesting that reactivations of TK-deficient HSV-2 may be possible. In general, viral heterogeneity is present in reactivatable HSV-2 with TK-deficient phenotypes, such that in vivo complementation of the predominant $\mathrm{TK}^{-}$ population by a $\mathrm{TK}^{-}$subpopulation may be taking place. ${ }^{30} 31$ Acyclovir-resistant reactivations from a patient following clearance of a resistant lesion may thus be either sensitive or resistant to acyclovir.

The establishment and maintenance of latency is a complex process whose outcome is determined by the sum total of the interaction of multiple cellular and viral factors. The nature of these interactions is still incompletely understood. Several lines of evidence suggest that the choice between latency or lytic pathways is determined very early after infection. Ganglionic cells showing no signs of lytic infection but harbouring latent virus are distinct from and appear simultaneously with ganglionic cells undergoing lytic infection, suggesting that initiation of lytic infection is not required for establishment of latency. ${ }^{32}$ Further, there is an absence of IE messenger RNAs by in-situ hybridisation in latentlyinfected cells. ${ }^{15}$ In fact, evidence from replication-incompetent mutants suggests that replication is not necessary for establishment of latency. ${ }^{33}$ Finally, there is evidence to suggest that restricted gene expression of LATs is an early event and can be detected as early as the fourth day following peripheral inoculation. ${ }^{34}$ There is general agreement, however, that there is more than one HSV genome per neuron. It is uncertain whether many virions initially infect the latent cell, whether the DNA is a remnant of early replication prior to establishment of latency or whether the DNA is actually replicated within the neuron following the establishment of latency. ${ }^{35}$ IE protein production, particularly $\alpha 4$ protein, is absolutely required for subsequent gene expression and is also responsible for most of the cell damage that eventuates in cell death. Therefore, this is the likely level at which restriction of gene expression occurs. ${ }^{36}$

Upon commencement of lytic infection the gene transcriptional cascade is initiated by the interaction of at least one viral and two host proteins. Transactivation of viral immediate early (IE or $\alpha$ genes) genes is initiated by VP16 which is already present in the tegument. VP 16 mediates this transactivation by forming a complex with at least two cellular factors, one of which is the Oct-1 transcription factor which is critical to enable binding of VP 16 to the octamer-like sequences in the IE gene promoter. ${ }^{36}$ Latent viral DNA is prob- ably circular and extrachromosomal, known to be associated with cellular histones and organised into nucleosomes which resemble chromatin, further suggesting that control of viral gene expression during latency is under cellular regulatory factors. ${ }^{38-40}$ The LAT gene may also have a role in maintenance of latency. It is antisense to but overlaps an IE gene, ICP 0 , and evidence suggests that it may inhibit the ICP 0 transcript, possibly by formation of an RNA duplex. ${ }^{343841}$ Contradicting this model is the behaviour of LAT negative mutants which are able to establish and maintain latency but are impaired in induced reactivation. ${ }^{42}$

The factors which cause genes to switch from latent to lytic gene expression are also largely unknown. Triggers of reactivation suggest that latency is a result of a lack of host factors which are critical for the expression of early gene proteins and that external stimuli may activate cellular transcription factors which can induce viral regulatory proteins and begin the lytic cycle. Many stimuli, including ganglionic explantation, have been shown to trigger neuronal transcription factors such as c-fos and c-jun which then alter neuronal gene expression $^{43}$ and explanted, latently infected mouse ganglia, demonstrate upregulation of cellular transcription factors, including Oct-1 which precedes viral RNA expression. ${ }^{44}$ How these transcription factors may switch genes from latent to lytic expression is unknown. The likely viral mediators of reactivation are the IE transcription factors, the first viral products to appear after explantation. ${ }^{45}$ Evidence suggests that ICP 0 may be the crucial viral gene which mediates the switch from latency to lytic cycle. ${ }^{134647}$ One model proposes that the number of viral DNA copies per cell determines the balance between latency and lytic infection and that perturbations which cause reactivations do so by stimulating DNA replication beyond a critical level where viral gene expression ensues. ${ }^{35}$

\section{Herpes meningitis}

HSV has been isolated from the CSF of $0.5 \%$ to $3 \%$ of patients presenting to hospital with aseptic meningitis. ${ }^{48}$ In both adults and infants HSV-2 is more commonly isolated than HSV-1. ${ }^{4}$ It has been estimated that only a third of patients with HSV-2 meningitis report genital lesions. ${ }^{49} 50 \mathrm{HSV}$ may also be isolated from the CSF of otherwise normal individuals. ${ }^{51} \mathrm{HSV}$ meningitis is usually seen in association with primary genital HSV infection where it has been reported to occur at an incidence of $36 \%$ in women and $13 \%$ of men with primary HSV-2 infections. ${ }^{4}$ In most cases symptomatically associated with genital herpes, genital lesions precede meningitis by a mean of approximately one week. ${ }^{52}$ The clinical cluster of symptoms includes headache, stiff neck, photophobia, malaise and fever and may be severe enough to require hospitalisation. The CSF typically demonstrates a lymphocytic pleocytosis ranging from 5 to greater than $1000 / \mathrm{mm}^{3}$ (median $300-400 / \mathrm{mm}^{3}$ ) and is usually associated with a glucose greater 


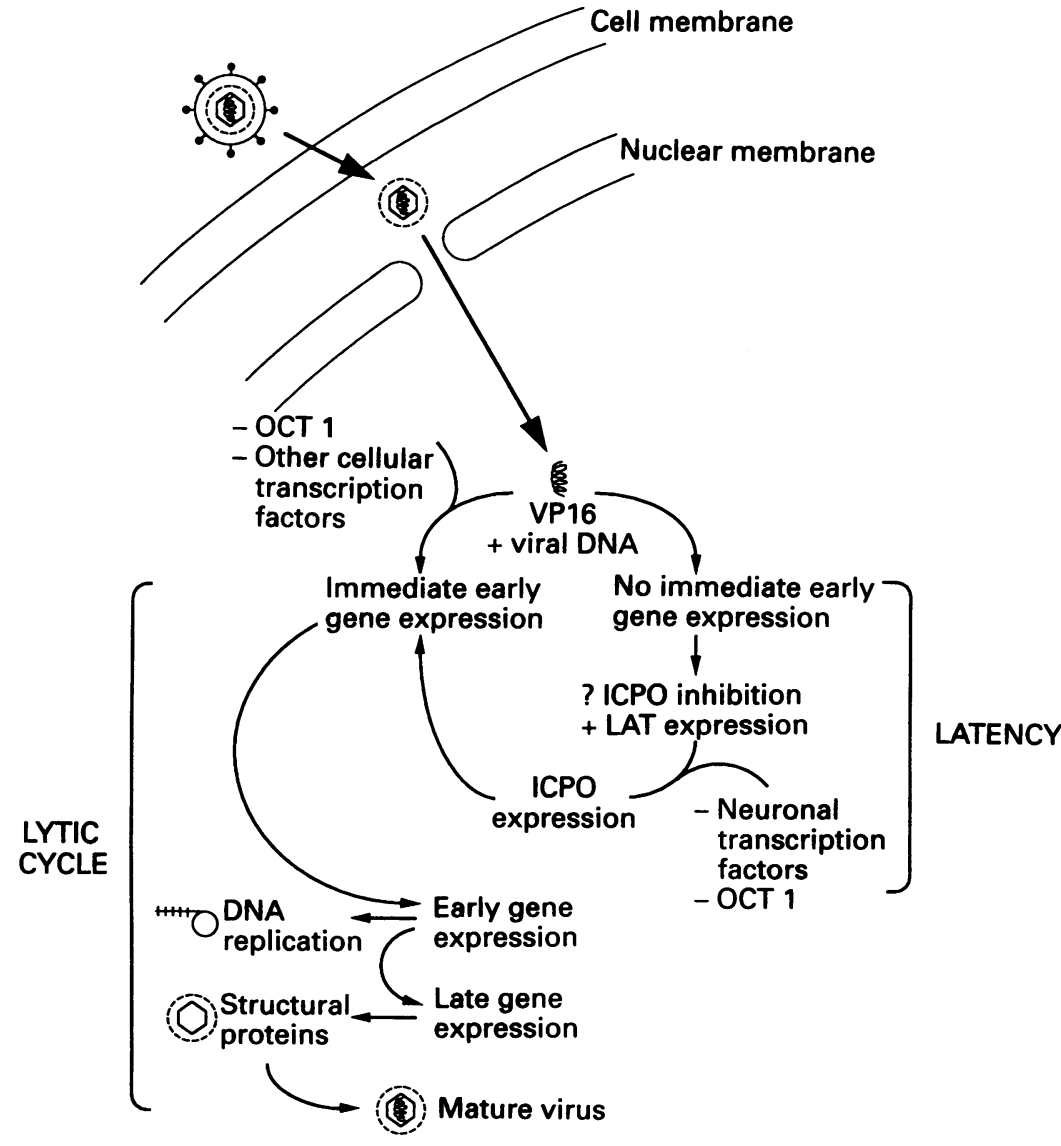

Figure 2 Schematic illustration of the cascade of gene expression involved in the genesis of lytic infection. Also shown are the putative regulatory factors involved directing infection to lytic or latent infection pathways as well as the factors involved in switching from latency to lytic infection. recurrent aseptic meningitis ${ }^{55}$ and three cases of recurrences of Mollaret's meningitis coincident with the development of genital herpes with subsequent responses to treatment with acyclovir (ACV), ${ }^{56}$ suggest $\mathrm{HSV}$ as a possible cause of this syndrome, a benign form of recurrent aseptic meningitis. Unfortunately, repeated isolation of $\mathrm{HSV}$ from these patients has not been documented and isolation of virus and antigen detection from the CSF of patients with likely HSV-2 recurrent meningitis has been unrewarding. It has been suggested that detection of intrathecal HSV-2 IgG antibody production by immunoblotting in CSF collected three or more days after onset of symptoms may be a useful diagnostic adjunct. ${ }^{52}$ There have also been reports of the diagnosis of HSV meningitis using the diagnostic sensitivity of CSF polymerase chain reaction (PCR) ${ }^{57}$ and further exploration with this technique may clarify many of the above unsolved issues and offer a diagnostic tool. HSV-2 may be a potential cause of many cases of aseptic meningitis that have previously been undiagnosable without a specific test. HSV PCR of the CSF is likely to demonstrate HSV-2 as the cause for many cases which might have previously been considered idiopathic.

Whether antiviral chemotherapy has any effect on prevention or course of meningeal disease is relatively unknown. Anecdotal reports in primary and recurrent infections suggest response to systemic treatment with acyclovir. ${ }^{56} 58$ This, together with the documented efficacy of acyclovir in primary infections, ${ }^{59}$ make its use for this indication compelling.

than $50 \%$ of the blood glucose although hypomore, it is likely that patients with symptomatic primary genital herpes whose extragenital symptoms include fever, and/or headache, and/or mild photophobia may have a low-grade meningitis. HSV-2 meningitis is generally self-limited resolving without long term neurological sequelae. ${ }^{4}$ However, transient neurological complaints have actually been reported in the majority of primary genital episode infections associated with meningitis. These included urinary retention, dysaesthesias, paresthaesias, neuralgia, motor weakness, paraparesis, concentration difficulties, periodic headache and impaired hearing. ${ }^{52}$ The frequency of recurrent meningitis has been reported at $18 \cdot 5-30 \% .{ }^{49} 52$

The genesis of HSV meningitis is unclear. Rare reports of the isolation of HSV in buffy coats of adults with meningitis together with the observation that HSV CSF isolation only tends to be associated with disseminated infection but not isolated encephalitis suggests a haematogenous route of infection ${ }^{54}$ and would also be consistent with the known pathogenesis of other viral meningitides. The association of meningitis with radiculitis and the existence of recurrent meningitis associated with genital recurrences, however, suggests that neurogenic spread may also occur and may partly explain the difficulty of recovery of virus from blood or CSF. ${ }^{5051}$

The isolation of HSV during a bout of

\section{Radiculomyelopathy}

Radiculomyelopathy presents clinically with numbness, paraesthesias, neuralgic pain of the buttock, perineum or lower limbs, urinary retention, constipation and/or impotence. Symptoms suggest a predominance of autonomic nervous system dysfunction. Physical examination may reveal sacral anaesthesia to fine touch, hypaeresthesia, reduced perineal and bulbocavernosus reflexes, reduced rectal sphincter tone and bladder distention. It is usually associated with CSF pleocytosis and elevated protein, may occur with a low glucose in the CSF and may precede and be associated with episodes of clinical aseptic meningitis. ${ }^{49}$ Electromyographic studies have shown slowed nerve conduction and fibrillation potentials. ${ }^{5660}$ In cases of neuropathic bladder, cystometric investigation reveals a flaccid hypotonic curve compatible with a lower motor neuron neuropathic bladder. ${ }^{60} 61$ Symptoms resolve gradually over days to weeks although residual urinary dysfunction, hypaesthesia, or lower extremity weakness may occasionally persist for months. ${ }^{5}$ In heterosexuals it is mainly a complication of primary infection in women ${ }^{4}$ but it has been reported to occur in $52 \%$ of homosexual men with HSV proctitis which may particularly predispose to this complication. ${ }^{62}$ Urinary retention associated with herpes genitalis 
patients occurs predominantly in females and retention follows lesions on average four days later. Overt signs of HSV infection, however, may be absent; hence HSV infection needs to be considered in the differential diagnosis of all urinary retention in young adults. ${ }^{6364}$ Normal urinary function usually recovers from three days to three weeks without relapse, ${ }^{60}$ although prolonged dysfunction has occurred in the setting of corticosteroid treatment and raises questions as to the wisdom of their use. ${ }^{51}$ It is still uncertain whether the pathogenesis involves direct viral inflammation or a post-infectious inflammatory demyelinating process. HSV has also been reported to cause a sciatica syndrome occurring premenstrually in premenopausal women with buttock lesions, which may occur in the absence of lesions and which is responsive to amantidine hydrochloride when given to prevent or abort episodes. ${ }^{65}$

A more common presentation of neurogenic pain and/or dysaesthesias occurs in the setting of reactivation disease where prodromal manifestations of local discomfort occur at the site of the coming lesion or less commonly, at a remote site within a similar ganglionic distribution. The frequency of such prodromes is approximately $90 \%$ and symptoms may occur in the absence of lesions, so called "nonlesional prodromes". ${ }^{66}$ Prodromal discomfort may last for hours to days and mimics the prodromal discomfort of VZV reactivation. Neuralgia in association with HSV recurrences, although well documented, has been reported rarely although clinical practice suggests it to occur far more frequently, leg and thigh pain being a frequent component of prodromal symptomatology. In contrast to herpes zoster, it is usually unassociated with neurological deficit. ${ }^{67}$ Rarely, the typical episodic prodromal pain of recurrent HSV infection becomes chronic and/or unrelenting, losing its periodicity and resembling the post-herpetic neuralgia of VZV and may be associated with permanent neurological deficit. ${ }^{130}$ Unfortunately, no specific test will currently provide an accurate determination regarding the potential viral aetiology of such symptoms. Probably, the majority of such cases which lack both periodicity with mucocutaneous infection and association with objective neurological deficits, are not caused by $\mathrm{HSV}$ at all-even in patients who have proven $\mathrm{HSV}$ infection. Alternatively, $\mathrm{HSV}$ has been a cause in some individuals, ${ }^{68}$ but like post-VZV neuralgia, long-term replication of HSV is not easy to identify even if present. Further, damage done to neurons may be manifested in a post-viral sense, the result of completed viral damage. There is no evidence that long-term or chronic HSV-related pain will respond to acyclovir intervention in the absence of genital sores. Indeed, one study of chronic oral acyclovir suggested an increase of unexplained nonlesional HSV episodes may occur during the early intervention period of acyclovir prophylaxis. ${ }^{69}$ Occasionally patients with this type of complaint will respond to acyclovir suppression, although the majority will not. For the indication of pain, alone, acyclovir should be tried only rarely, since it is not clear what its therapeutic role may be in the absence of regular genital mucocutaneous lesions.

HSV may also produce an ascending myelitis. This may be rapidly progressive, necrotising and fatal when it is usually associated with a purulent CSF. ${ }^{70}{ }^{71}$ Less fulminant cases are associated with an aseptic meningitis. ${ }^{51} 7273$ Cases occur in immunocompetent as well as immunocompromised hosts. AIDS patients may suffer an insidiously progressive myelopathy, ${ }^{74}$ dual infection of $\mathrm{HSV}$ with other viral pathogens such as CMV, and pathogenesis may differ with extensive infection occurring with minimal inflammation. ${ }^{75}$ Myelin basic protein has been suggested as a useful marker of disease activity. ${ }^{76}$ The pathogenesis of myelitis is also uncertain. The few documented pathological studies are consistent with immune-mediated demyelination ${ }^{70} 77$ and this has been supported by reports of response to and rebound on withdrawal of corticosteroids $^{51}$ although cord infection has also been demonstrated. ${ }^{74}$ In view of the difficulty of isolation of $\mathrm{HSV}$ from the CSF of patients with neurological dysfunction it is quite possible that some cases of idiopathic myelitis may be due to HSV and that its incidence may be much more frequent than is currently appreciated.

Treatment of radiculomyelitis includes management of urinary retention by either intermittent or continuous urinary catheterisation, associated with symptomatic pain relief as this may contribute to retention. In cases of persistent dysfunction a suprapubic catheter is recommended. ${ }^{63}$ Cholinergic and alpha-sympatholytic agents have also been used. ${ }^{40}$ Trials of antiviral agents in radiculomyelitis have not been carried out; however, anecdotal reports of responses to $\mathrm{ACV}$ and proven efficacy of ACV in primary and recurrent genital herpes suggest specific antiviral treatment is indicated. 597678

\section{Disseminated infection}

Disseminated HSV infection is usually seen in the setting of a host compromised by immunodeficiency such as bone marrow transplantation, malignancy (especially hematological in the setting of chemotherapy), malnutrition, alcoholism, pregnancy or the neonate. It is also seen in patients with integument defects such as burns and eczema, although cases in apparently normal hosts have been reported. ${ }^{59-86}$ Neonatal disease requires a review in itself and will not be more specifically addressed here.

Cell-mediated immune deficits seem most important. ${ }^{20}$ Even in the setting of profound immunosuppression, however, where HSV disease is typically chronic, erosive, and associated with prolonged viral shedding, only very rarely does $\mathrm{HSV}$ infection disseminate. 225487 When it does occur, dissemination may be either mucocutaneous or visceral or both. Mucocutaneous dissemination is an uncommon complication of primary genital 
HSV infection ${ }^{88} 89$ where anecdotal reports of a satisfactory response to acyclovir have been reported..$^{8590}$ Most recently, cases of thymidine kinase-deficient, acyclovir-resistant HSV have been reported to cause disseminated mucocutaneous disease in AIDS patients. ${ }^{91}$ Foscarnet has generally proven an efficacious alternative therapy. ${ }^{30}$ The true incidence of dissemination may be higher than appreciated as autopsy studies have reported up to $6 \%$ incidence of HSV visceral dissemination. ${ }^{92} 93$ Although visceral dissemination may be a multisystem disease, isolated organ involvement, particularly of oesophagus, lung and liver, may also occur.

The oesophagus is by far the most common viscus involved, the incidence in autopsy studies ranging from $0.5 \%$ to $6 \%$. It usually occurs as the sole organ involved. Antemortem diagnosis is rare and the majority of cases occur in the setting of malignancy. ${ }^{93} 94$ Oesophagitis may either result from direct extension from oropharyngeal disease or via reactivation through the vagus nerve. It presents with odynophagia, dysphagia, retrosternal and substernal pain, weight loss and fever although many cases are asymptomatic. On endoscopy one sees multiple oval ulcerations on an erythematous base with or without a white pseudomembrane. The distal oesophagus is most commonly involved. ${ }^{82} 95 \mathrm{HSV}-1$ is the usual aetiologic agent, although HSV-2 oesophagitis may occur. Although most cases are in immunocompromised hosts HSV oesophagitis does occur in normal hosts where it usually is part of a primary infection in males. The clinical course is self limited in normal hosts but progressive in compromised hosts if left untreated. Investigation by double contrast oesophagoscopy may display discrete, shallow, widely scattered ulcers. Endoscopy has the highest sensitivity and is the diagnostic procedure of choice, most commonly demonstrating discrete ulcers with a yellow rim of exudate or ulcer base, socalled "volcano ulcers" ${ }^{94}$ Differentiation from other causes of oesophagitis such as candida and peptic oesophagitis cannot be reliably made clinically and diagnosis relies on culture or cytological examination of biopsy specimens or aspirates. ${ }^{84}$ Candida and HSV may coexist as causes for oesophagitis. Other pathogens are common and it has been suggested that herpetic ulcers may provide a portal of entry for these which may contribute to pathology. ${ }^{92} 94$

It has been reported that $0 \cdot 3 \%-1 \cdot 0 \%$ of all patients examined at autopsy have histological evidence of involvement with $\mathrm{HSV}$ of the lower respiratory tract, either as tracheobronchitis or pneumonia. ${ }^{8796}$ In bone marrow recipients, HSV accounts for $6 \%$ of histologically-confirmed interstitial pneumonitis, usually the result of endogenous reactivation, with either local extension of oral herpetic infection down the tracheobronchial tree into lung parenchyma resulting in focal necrotising pneumonia or haematogenous spread from oral or genital mucocutaneous lesions to result in bilateral interstitial pneumonitis. ${ }^{79}$ It is interesting that latent $\mathrm{HSV}$ has also been found in human vagal ganglia. Thus, reactivation with neurogenic spread may also provide a possible mechanism of both respiratory and oesophageal infection. ${ }^{98}$ Tracheal trauma due to intubation (which may also predispose to aspiration), burns, ${ }^{94} 9699$ or areas of squamous metaplasia from smoking ${ }^{100}$ can also predispose to direct spread. Clinical and radiological findings are nonspecific and include fever, cough, respiratory insufficiency and focal or diffuse pulmonary infiltrates. Mucocutaneous HSV lesions often antedate pneumonia but may be absent. ${ }^{79} 101$ Other serious concomitant bacterial and fungal pathogens are common. ${ }^{95}$ Mortality is high ${ }^{79}$ but, untreated, the illness is not invariably fatal, particularly in normal hosts, and the incidence of mild self-resolving disease is unknown. ${ }^{79} 99 \mathrm{HSV}$ has been reported to occur in $30 \%$ of intubated patients with acute respiratory distress syndrome (ARDS). Such patients have more respiratory insufficiency than those without HSV but the relationship of HSV to the pathogenesis of ARDS is uncertain. ${ }^{99}$ Diagnosis is dependent on histological evidence of pneumonia together with isolation of virus from lung and investigation should include bronchoscopy which may visualise ulcerations or membranes of the respiratory tract and which allows collection of cytological specimens by washings and brushings and histological specimens by biopsy. Viral culture of sputum or throat washings, alone, are often falsely positive due asymptomatic salivary shedding in ill patients. Direct immunofluorescence or immunoperoxidase staining of infected tissue may also be helpful in establishing the presence of infection rapidly. ${ }^{100}$

HSV is an uncommon cause of viral hepatitis. In solid organ transplant recipients it occurs at a frequency of $0.3 \%$ and is an early manifestation, occurring a median of 18 days (range 5-46) post transplant, sooner than cytomegalovirus (CMV) infection which occurs 30-40 days post transplantation. It can occur as either primary or reactivation disease. The majority of cases of HSV hepatitis occur in the setting of disseminated infection, however, isolated hepatitis may also occur. Concomitant dissemination is reflected in a reported mortality rate of $60-86 \%$, even in normal hosts. ${ }^{86}{ }^{102-104}$ Pathology may be focal, associated with a good prognosis and response to antiviral chemotherapy or diffuse, associated with disseminated intravascular coagulation (DIC) and a poor prognosis regardless of antiviral intervention. ${ }^{102}$ Hepatitis is the most common manifestation of dissemination in pregnancy where it is most often associated with primary infection in the third trimester and results in a $60 \%$ fetal wastage rate. 90104 Clinical and laboratory presentations include fever, abdominal pain and tenderness, elevations of bilirubin and transaminases, either leukopenia or leukocytosis, increased band forms, atypical lymphocytes, DIC, and abnormal chest radiograms. Only 25-94\% of patients have associated mucocutaneous disease and the absence of such lesions should 
not deter the clinician from entertaining the diagnosis. ${ }^{86}{ }^{102-105}$ Over half of cases are diagnosed in extremis or post mortem. Associated extrahepatic visceral involvement is common and is rarely diagnosed antemortem. Notably, the majority of cases of HSV hepatitis are anicteric. Accordingly, a high degree of suspicion in appropriate patients is required. In view of the fulminant nature of the disease, suspected cases should be treated with empirical antivirals immediately. Fourteen percent of healthy adults with acute primary or recurrent genital herpes may also have minor elevations of liver enzymes, suggesting minor cases of hepatitis may be more frequent than currently appreciated, although this is highly speculative. ${ }^{106}$ Diagnosis rests on detection of virus by culture or histopathology in liver biopsy specimens.

Other rarely reported manifestations of disseminated infection include monoarticular arthritis, idiopathic thrombocytopenia, glomerulonephritis, colitis, localised lymphadenitis and haemorrhagic cystitis possibly precipitated by catheterisation, adrenal necrosis, pancreatitis, encephalitis, myocarditis and splenic infection. ${ }^{107-118}$

Acyclovir is effective therapy and is superior to vidarabine, as evidenced by treatment trials against HSV encephalitis in man, as well as studies of disseminated HSV infection in animal models. ${ }^{121}$ Anecdotal reports of acyclovir efficacy, ${ }^{90} 94102103 \quad 122-125$ the proven efficacy of this treatment for genital herpes $^{59786}$ as well as the severity of infection mandate therapy with acyclovir. Another systemic antiviral, penciclovir, or its oral formulation, famciclovir, ${ }^{127}$ has not been specifically used in this setting, but may prove to be interesting alternatives for the future. Furthermore, valaciclovir, a much more bioavailable prodrug of acyclovir is currently undergoing extensive clinical study. Prophylaxis with oral acyclovir in immunocompromised hosts has also been found to be efficacious and has been reported to eliminate dissemination in one centre. ${ }^{102128}$ Of more recent concern is a report of ACV-resistant herpes oesophagitis due to a polymerase mutant, ${ }^{129}$ as well as proof of establishment of latent resistant $\mathrm{HSV}$ in a nonimmunocompromised host. ${ }^{130}$ With an ever growing immunocompromised population, HSV resistance is likely to occur with increasing frequency.

\section{Conclusions}

This review has tried to shed some light on and bring up to date the gradually unravelling enigma of how HSV establishes, maintains itself in and reactivates itself from latency, a phenomenon fundamental to the pathogenesis of herpes virus infections. In addition, it has sought to elucidate the presentations, pathogenesis and treatment of several lesser known neurological manifestations as well as the potentially disastrous complication of disseminated infection, which continues to increase owing to an ever increasing popu- lation of immunocompromised individuals, in turn caused by more widespread organ transplantation as well as the growing HIV pandemic.

1 Johnson RE, Nahmias AJ, Magder LS, et al. A seroepidemiologic survey of the prevalence of herpes simplex virus type 2 infection in the United States. $N$ Engl $\mathcal{f}$ Med 1989;321:7-12.

2 Mertz GJ, Benedetti J, Ashley R, et al. Risk factors for the sexual transmission of genital herpes. Ann Intern Med 1992;116:197-202.

3 Hirsch MS. Herpes simplex virus. In: Mandell GL, Douglas RG, Bennett JE eds. Principles and Practice of Infectious Diseases. 3rd ed. New York: Churchill Livingstone, 1990:1144-53.

4 Corey L, Adams HG, Brown ZA, Holmes KK. Genital herpes simplex virus infections: clinical manifestations, course and complications. Ann Intern Med 1983;98. 958-72.

5 Corey L, Spear PG. Infections with herpes simplex viruses. $N$ Engl $\mathcal{F}$ Med 1986;314:686-91.

6 Poffenberger KI, Roizman B. Studies of a non-inverting genome of a viable herpes simplex virus. $\mathcal{f}$ Virol 1985 ; 53:589-95.

7 Hammerschmidt W, Sugden B. DNA replication of herpesviruses during the lytic cycle of their life-cycles. Mol Biol Med 1990;7:45-57.

8 Lycke E, Hamark B, Johansson M, et al. Herpes simplex virus infection of the human sensory neuron. An electron microscopy study. Arch Virol 1988;101:87-104.

9 Valee RB, Schpetner HS, Paschal BM. The role of dynein in retrograde axonal transport. Trends Neurol Sci 1989 12:3-7.

10 Stevens JG, Cook ML. Latent herpes simplex virus in spinal ganglia of mice. Science 1971;173:843-5.

11 Baringer JR, Griffith JF. Experimental herpes simplex encephalitis: early neuropathologic changes. $f$ Neuropathol Exp Neurol 1970;29:89-104.

12 Margolis TP, Lavail JH, Setzer PY, Dawson CR. Selective spread of herpes simplex virus in the central nervous system after ocular inoculation. F Virol 1989;63 4756-61.

13 Roizman B, Sears AE. Herpes simplex viruses and their replication. In: Fields BN and Knipe DM eds. Virology. 2nd ed. New York: Raven Press, 1990:1795-841.

14 Stevens JG, Wagner EK, Devi-Rao GB, et al. RNA complementary to a herpesvirus alpha gene mRNA is prominent in latently infected neurons. Science 1987;235: nent in $1056-9$.

15 Croen KD, Ostrove JM, Dragovic LJ, et al. Latent herpes simplex virus in human trigeminal ganglia. Detection of an intermediate early gene antisense transcript by in situ an intermediate early gene antisense transcript by
hybridisation. $N$ Engl $\Im$ Med 1987;317:1427-32.

16 Croen KD, Ostrove JM, Dragovic L, Strauss SE. Characterization of herpes simplex virus type 2 latencyassociated transcription in human sacral ganglia and in cell culture. F Infect Dis 1991;163:23-8.

17 Richards JT, Kern ER, Overall JC, Glasgow LA. Differences in neurovirulence of herpes simplex virus types 1 and 2 in mice using four routes of infection. f Infect Dis 1981;144:464-71.

18 Lafferty WE, Coombs RW, Benedetti J, et al. Recurrences after oral and genital herpes infection and viral type. after oral and genital herpes in

19 Knox SR, Corey I, Blough HA, Lerner AM. Historical findings in subjects from a high socioeconomic group who have genital infections with herpes simplex virus. Sex Transm Dis 1982;9:15-20.

20 Rand KH, Rasmussen LE, Pollard RB, et al. Cellular immunity and herpesvirus infections in cardiactransplant patients. $N$ Engl $\mathcal{F}$ Med 1977;296:1372-7.

21 Corey L, Reeves WC, Holmes KK. Cellular immune response in genital herpes simplex virus infection. $N$ Engl f Med 1978;299:986-91.

22 Meyers JD, Flournoy N, Thomas ED. Infection with herpes simplex virus and cell-mediated immunity after marrow simplex virus and cell-mediated immunity

23 Siegal FP, Lopez C, Hammer GS, et al. Severe acquired immunodeficiency in male homosexuals, manifested by chronic perianal ulcerative herpes simplex lesions. N Engl F Med 1981;305:1439-44.

24 Price RW, Schmitz J. Reactivation of latent herpes simplex virus infection of the autonomic nervous system by postganglionic neurectomy. Infection Immun 1978;19. 523-32.

25 Kastrukoff L, Long C, Doherty PC, et al. Isolation of virus from brain after immunosuppression of mice with latent herpes simplex. Nature 1981;291:432-3.

26 Pazin GJ, Armstrong JA, Lam MT, Tarr GC. Prevention of reactivated herpes simplex infection by human leucocyte interferon after operation on the trigeminal leucocyte interferon after operation
root. $N$ Engl $\Im$ Med 1978;301:225-30.

27 Perna J, Mannix ML, Rooney JF, et al. Reactivation of latent herpes simplex virus infection by ultraviolet light: a latent herpes simplex virus infection by ultraviolet lig
human model. $₹ \mathrm{Am}$ Acad Dermatol 1987;17:473-8.

28 Gominak S, Cros D, Paydarfar D. Herpes simplex labialis and trigeminal neuropathy. Neurology 1990;40:151-2.

29 Coen DM, Kosz-Vnenchak M, Jacobson J, et al. Thymidine kinase-negative herpes simplex virus mutants establish latency in mouse trigeminal ganglia but do not 
reactivate. Proc Natl Acad Sci USA 1989;86:4736-40.

30 Safrin S, Assaykeen T, Follansbee S, Mills J. Foscarne therapy for acyclovir-resistant herpes simplex virus infection in 26 AIDS patients: preliminary data. $\mathcal{F}$ Infect Dis 1990;161:1078-84.

31 Sasadeusz J, Sacks SL. Spontaneous reactivation of acyclovir (ACV)-resistant $\left(\mathrm{ACV}^{\mathrm{r}}\right)$, thymidine kinase deficient $\left(\mathrm{TK}^{-}\right)$herpes simplex virus (HSV): masked heterogeneity or revertant? Abstract PoB 3577, VII International Conference on AIDS/III STD World Congress, Amsterdam, the Netherlands, 19-24 July 1992.

32 Speck PG, Simmons A. Divergent molecular pathways of productive and latent infection with a virulent strain of herpes simplex virus type 1. F Virol 1991;65:4001-5.

33 Katz JP, Bodin ET, Coen DM. Quantitative polymerase chain reaction analysis of herpes simplex virus DNA in ganglia of mice infected with replication-incompetent ganglia of mice infected with replic

34 Roizman B, Sears AE. An inquiry into the mechanisms of herpes simplex latency. Ann Rev Microbiol 1987, 41.543-71.

35 Spivack JG, Fraser NW. Expression of herpes simplex type 1 latency-associated transcripts in the trigeminal ganglia of mice during acute infection and reactivation from latent infection. $\mathcal{F}$ Virol $1988 ; 62: 1479-85$.

36 Saers AE. Mechanisms of restriction of viral gene expression during herpes simplex virus latency. In: C Lopez, $R$ Mori, B Roizman, RS Whitley, eds. Immunobiology and Prophylaxis of Human Herpesvirus Infections. New York Plenum Press 1990;211-217.

37 Kristie TM, Roizman B. Host cell proteins bind to the cisacting site required for virion-mediated induction of herpes simplex virus 1 \&̊ genes. Proc Natl Acad Sci USA 1987;84:71-5.

38 Fraser NW, Spivack JG, Wroblewska Z, et al. A review of the molecular mechanisms of HSV-1 latency. Curr Eye the molecular mechanism

39 Deshmane S, Fraser NW. During latency, herpes simplex virus type-1 DNA is associated with nucleosomes in chromatin structure. F Virol 1989;63:943-7.

40 Latchman DS. Current status review: Molecular biology of herpes simplex virus latency. F Exp Pathol 1990;71: 133-41.

41 Farrell MJ, Dobson AT, Feldman LT. Herpes simplex virus latency-associated transcript is a stable intron. Proc Natl Acad Sci USA 1991;88:790-4.

42 Hill JM, Sedarati F, Javier RT, et al. Herpes simplex virus latent phase transcription facilitates in vivo reactivation. Virology 1990;174:117-25.

43 Sheng M, Greenberg ME. The regulation and function of cfos and other immediate-early genes in the nervous system. Neuron 1990;4:477-85.

44 Valyi-Nagy $T$, Deshmane $S$, Dillner A, Fraser NW Induction of cellular transcription factors in trigemina ganglia of mice by corneal scarification, herpes simplex ganglia of mice by corneal scarification, herpes simplex type 1 infection, and exp

45 Wroblewska Z, Savage K, Spivak JG, Fraser N. Detection of HSV-1 proteins prior to the appearance of infectious virus in mouse trigeminal ganglia during reactivation of latent infection. Virus Res 1989;14:95-106.

46 Harris RA, Everett RD, Zhu X, et al. Herpes simplex type 1 immediate-early protein Vmw110 reactivates latent herpes simplex virus type 2 in an in vitro latency system. $\ngtr$ Virol 1989;63:3513-5.

47 Leib DA, Coen DM, Bogard CL, et al. Immediate-early regulatory gene mutants define different stages in the establishment and reactivation of herpes simplex virus latency. $₹$ Virol 1989;63:759-68.

48 Olson LC, Buescher EL, Atenstein MS, Parkman PD. Herpesvirus infections of the human nervous system Herpesvirus infections of the hur 19 Med 1967;277:1271-7.

49 Hevron JE. Herpes simplex virus type 2 meningitis. Obstetr Gynecol 1977;49:622-4.

50 Skoldenberg B, Jeansson S, Wolontis S. Herpes simplex virus type 2 and acute aseptic meningitis. Scand $\mathcal{f}$ Infect Dis 1975;7:227-32.

51 Craig C, Nahmias A. Different patterns of neurologic involvement with herpes simplex types 1 and 2: isolation of herpes simplex virus from the buffy coat of two adults with meningitis. F Infect Dis 1973;127:365-72.

52 Bergstrom T, Vahlne A, Alestig K, et al. Primary and recurrent herpes simplex virus type-2 meningitis. F Infect Dis 1990;162:322-30.

53 Brenton DW. Hypoglycorrhachia in herpes simplex type 2 meningitis. Arch Neurol 1980;37:317.

54 Meyers JD, Wade JC, Mitchell CD, et al. Multicenter collaborative trial of intravenous acyclovir for treatment of mucocutaneous herpes simplex virus infection in the immunocompromised host. Am $¥$ Med 1982 Acyclovir immunocompromised

55 Steel JG, Dix RD, Baringer JR. Isolation of herpes simplex type 1 in recurrent (Mollaret) meningitis. Ann Neurol 1982;11:17-21.

56 Berger JR. Benign aseptic (Mollaret's) meningitis after genital herpes. Lancet 1991;337:1360-1.

57 Aslanzadeh J, Osmon DR, Wilhelm MP, et al. A prospective study of the polymerase chain reaction for detection of herpes simplex virus in cerebrospinal fluid submitted to the clinical virology laboratory. Mol Cell Probes 1992 6:367-73.

58 Bergstrom $T$, Alestig $K$. Treatment of primary and recurrent herpes simplex virus type 2 induced meningitis with acyclovir. Scand F Infect Dis 1990;22:239-40.
59 Bryson YL, Dillon M, Lovett M, et al. Treatment of first episodes of genital herpes simplex virus infection with oral acyclovir. $N$ Engl $\mathcal{F}$ Med 1983;308:916-21.

60 Caplan LR, Kleeman FJ, Berg S. Urinary retention probably secondary to herpes genitalis. $N$ Engl f Med 1977; 297:920-1

61 Riehle RA, Williams J. Transient neuropathic bladder following herpes simplex genitalis. $\mathcal{F}$ Urol 1979;122 263-4.

62 Goodell SE, Quinn TC, Mkrtichian E, et al. Herpes simplex proctitis in homosexual men: clinical, sigmoido-
scopic, and histopathologic features. $N$ Engl $\mathfrak{F}$ Med 1983, 308:868-71.

63 Hemrika DJ, Schutte MF, Bleker OP. Elsberg syndrome: a neurological basis for acute urinary retention in patients with genital herpes. Obstet Gynecol 1986;68(Suppl):37S9S.

64 Steinberg J, Rukstalis DB, Vickers MA Jr. Acute urinary retention secondary to herpes simplex meningitis. F Urol 1991;145:359-60.

65 Fisher DA. Recurrent herpes simplex sciatica and its treatment with amantidine hydrochloride. Cutis 1982;29. 467-72.

66 Sacks SL. Frequency and duration of patient-observed recurrent genital herpes simplex virus infection: characterization of the nonlesional prodrome. $\mathcal{F}$ Infect $D i$ 1984;150:873-7.

67 Layzer RB, Conant MA. Neuralgia in recurrent herpes simplex. Arch Neurol 1974;31:233-7.

68 Krohel GB, Richardson JR, Farrell DF. Herpes simplex neuropathy. Neurology 1976;26:596-7.

69 Sacks SL, Fox R, Levendusky P, et al. Chronic suppression for six months compared with intermittent lesional therapy of recurrent genital herpes using oral acyclovir: effects on lesions and nonlesional prodromes. Sex Trans Dis 1988;15:58-63.

70 Klatersky J, Cappel R, Snoeck JM, et al. Ascending myelitis in association with herpes-simplex virus. $N$ Engl myelitis in association wi

71 Wiley CA, Van Patten PD, Carpenter PM, et al. Acute ascending necrotizing myelopathy caused by herpes simplex type 2. Neurology 1987;37:1791-4.

72 Thomas EE, Scheifele DW, MacLean BS, et al. Herpes simplex type 2 aseptic meningitis in a two-month old infant. Pediatr Infect Dis $\mathcal{f} 1989 ; 8: 184-6$.

73 Shturman-Ellstein R, Borkowsky W, Fish I, et al. Myelitis associated with genital herpes in a child. $\mathcal{F}$ Pediatr 1976 88:523

74 Britton CB, Mesa-Tejada R, Fenoglio CM, et al. A new complication of AIDS: Thoracic myelitis caused by herpes simplex virus. Neurology 1985;35:1071-4.

75 Tucker T, Dix RD, Katzen C, et al. Cytomegalovirus and herpes simplex virus ascending myelitis in a patient with acquired immune deficiency syndrome. Ann Neurol 1985;18:74-9.

76 Ahmed I. Survival after herpes simplex type II myelitis. Neurology 1988;38:1500.

77 Lipton HL and Teasdall RD. Acute transverse myelopathy in adults. Arch Neurol 1973;28:252-7.

78 Reichman RC, Badger GJ, Mertz GJ, et al. Treatment of recurrent genital herpes simplex infections with oral acyclovir. A controlled trial. $\mathfrak{f} A M A$ 1984;251:2103.

79 Ramsey PG, Fife KH, Hackman RC, et al. Herpes simplex virus pneumonia: clinical, virologic and pathologic features in 20 patients. Ann Intern Med 1982;97:813.

80 Whitley RJ, Levin M, Barton N, et al. Infections caused by herpes simplex virus in the immunocompromised host: natural history and topical acyclovir therapy. $\mathcal{F}$ Infect $D$ is 1984;150:323.

81 Foley FD, Greenwald KA, Nash G, et al. Herpesvirus infection in burned patients. $N$ Engl $f$ Med 1970 282:652.

82 Hazen PG, Bennett-Eppes R. Eczema herpeticum caused by herpesvirus type 2 . A case in a patient with Darie disease. Arch Dermatol 1977:113:1085.

83 Peacock JE Jr, Sarubbi FA. Disseminated herpes simplex virus infection during pregnancy. Obstet Gynecol 1983 61:Suppl 3:13S-18S.

84 Galbraith JCT, Shafran SD. Herpes simplex esophagitis in the immunocompetent patient: report of four patients and review. Clin Infect Dis 1992;14:894-901.

85 Pol S, Durand F, Bernau J, et al. Herpesvirus infection of the respiratory tract in patients with alcoholic hepatitis. Alcohol Clin Exp Res 1992;16:979-81.

86 Chase RA, Pottage JC Jr, Haber MH, et al. Herpes simplex viral hepatitis in adults: two case reports and review of
the literature. Rev Infect Dis 1987;9:329-33.

87 Whitley RJ, Levin M, Barton N, et al. Infections caused by herpes simplex virus in the immunocompromised host: 1984;150:323-9.

88 Nahmias AJ. Disseminated herpes simplex virus infections. N Engl f Med 1970;282:684

89 Gutman DH, Beard BA, Collinge ML. Nonfatal disseminated mucocutaneous herpes simplex type 2 infection in a healthy adult woman. Obstet Gynecol 1988;72: 506-7.

90 Cox SM, Phillips LE, DePaolo HD, Faro S. Treatment of disseminated herpes simplex virus in pregnancy with parenteral acyclovir. A case report. F Reprod Med 1986 31:1005-7.

91 Marks GL, Nolan PE, Erlich KS, Ellis MN. Mucocutaneous dissemination of acyclovir-resistant herpes simplex virus in a patient with AIDS. Rev Infect Dis 1989;11:474-6. 
92 Buss DH, Scharyi M. Herpesvirus infection of the esophagus and other visceral organs in adults. Incidence and clinical significance. Am $f$ Med 1979; 66:457-62.

93 Matsumoto J, Sumiyoshi A. Herpes simplex esophagitis-a study in autopsy series. Am 7 Clin Pathol 1985; 84:96-99.

94 Agha FP, Horchang HL, Nostrant TT. Herpetic esophagitis: a diagnostic challenge in immunocompromised patients. Am $\mathcal{f}$ Gastroenterol 1986;81:246-53.

95 Shortsleeve MJ, Gauvin GP, Gardner RC, Greenberg MS. Herpetic esophagitis. Radiology 1981;141:611-7.

96 Nash G. Necrotizing tracheobronchitis and bronchopneumonia consistent with herpetic infection. Hum Pathol 1972:3:283-91.

97 Nash G, Foley FD. Herpetic infection of the middle and lower respiratory tract. Am $f$ Clin Pathol 1970;54: 857-63.

98 Warren KG, Brown SM, Wroblewska A, et al. Isolation of latent herpes simplex virus from the superior cervical Med 1978;298:1068-9.

99 Tuxen DV, Cade JF, McDonald MI, et al. Herpes simplex virus from the lower respiratory tract in adult respiplex virus from the lower respiratory tract in adult respiratory dis-9.

100 Graham BS, Snell JD. Herpes simplex virus infection of the adult respiratory tract. Medicine (Baltimore) 1983; 62:384-93.

101 Hull HF, Blumhagen JD, Benjamin D, et al. Herpes simplex viral pneumonitis in childhood. $\mathcal{F}$ Pediatr 1984 104:211-5.

102 Kusne S, Schwartz M, Breinig MK, et al. Herpes simplex virus hepatitis after solid organ transplantation in adults. F Infect Dis 1991;163:1001-7.

103 Baxter RP, Phillips LE, Faro S, Hoffman L. Hepatitis due to herpes simplex virus in a nonpregnant patient:
treatment with acyclovir. Sex Transm Dis 1986;13: treatme

104 Goyert GI, Bottoms SF, Sokol RJ. Anicteric presentation of fatal herpetis hepatitis in pregnancy. Obstet Gynecol 1985;65:585-8

105 Eron L, Kosinski K, Hirsch MS. Hepatitis in an adult caused by herpes simplex virus type 1. Gastroenterology 1976;71:500-4.

106 Minuk GY, Nicolle LE. Genital herpes and hepatitis in healthy young adults. $f$ Med Virol 1986;19:269-75.

107 Steitman K, Beregi E, Hollos I, Turi S. Herpesnephropathy. Clin Nephrol 1977;7:106-11.

108 Schlesinger JJ, Gandara D, Bensch KG. Myoglobinuria associated with herpes-group viral infections. Arch Intern Med 1978;138:422-4.

109 Friedman HM, Pincus T, Gibilisco P, et al. Acute monoarticular arthritis caused by herpes simplex virus monoarticular arthritis caused by herpes simple
and cytomegalovirus. Am $¥ \mathrm{Med} 1980 ; 69: 241-7$.

110 Whittaker JA, Hardison JE. Severe thrombocytopenia after generalised herpes simplex virus-2 (HSV-2) infection. South Med F 1978;71:864-5.

111 Boulton AJM, Slater DN, Hancock BW. Herpesvirus colitis: a new cause of diarrhoea in a patient with Hodgkin's disease. Gut 1982;23:247-9.
112 Epstein JI, Ambinder RF, Kuhajda FP, et al. Localised herpes simplex lymphadenitis. Am f Clin Pathol 1986; 86:444-8

113 DeHertogh DA, Brettman LR. Hemorrhagic cystitis due to herpes simplex virus as a marker of disseminated herpes infection. Am F Med 1988;84:632-5.

114 Joseph TJ, Vogt PJ. Disseminated herpes with hepatoadrenal necrosis in an adult. $A m \mathcal{F} M e d$ 1974;56:735-9.

115 Young EJ, Killam AP, Greene JF Jr. Disseminated herpesvirus infection. $\mathcal{F A M A}$ 1976;235:2731-3.

116 Bell RW, Murphy WM. Myocarditis in young military personnel. Am Heart $\mathcal{f}$ 1967;74:309-23.

117 Anderson JM, Nicholls NWM. Herpes encephalitis in pregnancy. $B M \mathcal{F}$ 1972;1:632.

118 Zimmerli $W$, Bianchi L, Gudat $F$, et al. Disseminated herpes simplex type 2 and systemic candida infection in a patient with previous asymptomatic human immunodeficiency virus infection. $\mathcal{F}$ Infect Dis 1988;157:597-8.

119 Skoldenberg B, Alestig K, Burman L, et al. Acyclovir versus vidarabine in herpes simplex encephalitis. patients. Lancet 1984;ii:707-711.

120 Whitley RJ, Alford CA, Hirsch MS, et al. Vidarabine versus acyclovir therapy in herpes simplex encephalitis. sus acyclovir therapy in herpes

121 Kern ER, Richards JT, Overall JC Jr. Acyclovir treatment of disseminated herpes simplex virus type 2 infection in weanling mice: alteration of mortality and pathogenesis. weanling mice: alteration of m
Antiviral Res 1986;6:189-95.

122 McDonald GB, Sharma P, Hackman RC, et al. Esophageal infections in immunosuppressed patients after marrow transplantation. Gastroenterology 1985;88: 111-7.

123 Rattner HM, Cooper DJ, Zaman MB. Severe bleeding from herpes esophagitis. Am $\mathcal{f}$ Gastroenterol 1985;80: 523-5.

124 Lagrew DC, Furlow TG, Hager D, et al. Disseminated herpes simplex virus infection in pregnancy: Successful herpes simplex virus infection in pregnancy: Successfuct

125 McMinn PC, Lim IS, McKenzie PE, et al. Disseminated herpes simplex virus infection in an apparently immuherpes simplex virus infection in an apparently imm
nocompetent woman. Med $\mathcal{F}$ Aust 1989;151: 588-94.

126 Shepp DH, Newton BA, Dandliker PS, et al. Oral acyclovir therapy for mucocutaneous herpes simplex virus infections in immunocompromised marrow transplant recipients. Ann Intern Med 1985;102:783-5.

127 Vere-Hodge RA. Famaclovir and peraclovir. The mode of action of famaclovir including its conversion to peraclovir. Antiviral Chem Chemother 1993;4:467-84.

128 Wade JC, Newton B, Flournoy N, et al. Oral acyclovir for prevention of herpes simplex virus reactivation after marrow transplantation. Ann Intern Med 1984;100: marrow

129 Sacks SL, Wanklin RJ, Reece DE, et al. Progressive esophagitis from acyclovir-resistant herpes simplex. Clinical roles for DNA polymerase mutants and viral heterogeneity? Ann Intern Med 1989;111:893-9.

130 Kost RG, Hill EL, Tigges M, Strauss SE. Brief report: recurrent acyclovir-resistant genital herpes in an immunocompetent patient. $N$ Engl $f$ Med 1993;329. 1777-82. 